This is the peer reviewed version of the following article: Márquez-Ruiz, G. , Ruiz-Méndez, M. V. and Velasco, J. (2014), Antioxidants in frying: Analysis and evaluation of efficacy. Eur. J. Lipid Sci. Technol., 116: 1441-1450, which has been published in final form at https:// doi.org/10.1002/ejlt.201400063. This article may be used for non-commercial purposes in accordance with Wiley Terms and Conditions for Self-Archiving

\title{
ANTIOXIDANTS IN FRYING: ANALYSIS AND EVALUATION OF EFFICACY
}

Gloria Márquez-Ruiza, Mª Victoria Ruiz-Méndez ${ }^{\mathrm{b}}$ Joaquín Velasco $^{\mathrm{b}}$

anstituto de Ciencia y Tecnología de Alimentos y Nutrición (ICTAN-CSIC).

José Antonio Novais, 10. 28040-Madrid (Spain)

${ }^{\mathrm{b}}$ Instituto de la Grasa (IG-CSIC). Avda. Padre García Tejero, 4. 41012-Sevilla (Spain)

\section{Corresponding author}

Gloria Márquez-Ruiz

Instituto de Ciencia y Tecnología de Alimentos y Nutrición (ICTAN-CSIC).

José Antonio Novais, 10, 28040-Madrid (Spain)

Phone: +34 915492300

e-mail: gmarquez@ictan.csic.es 


\section{ABSTRACT}

This review is focused on the analysis and evaluation of efficacy of antioxidants in frying. Specific aspects of the action of natural and synthetic antioxidants at high temperature are discussed, and the most important methods used for the analysis of antioxidants and their efficacy are described. The action of antioxidants is well known under room temperature conditions during storage or at the moderate temperatures of the accelerated tests used to measure the oil stability. However, under frying conditions, involving oxidative and thermal reactions, evaluation of antioxidant efficacy is far more complicated. The application of antioxidants at the high temperature of frying requires special considerations, especially those based on stability and volatility. Also, the need for development of standardized methods to analyze natural antioxidants of potential use as additives, especially polyphenols present in plant extracts, stands out.

\section{Keywords}

Frying - Oxidation - Antioxidants - Tocopherols - Dimethylpolysiloxane - Polyphenols - Additives

\section{Running title}

Antioxidants in frying 


\section{INTRODUCTION}

Frying is one of the most commonly used cooking procedures in household, restaurants, fast-food outlets and food industry. During frying, numerous reactions due to the action of oxygen, high temperature and the water released by the food occur giving rise to oxidation, hydrolysis, polymerization, cyclization and isomerization of especially the main oil constituents, i.e. triacylglycerols [1, 2]. At the high temperatures of frying, alkyl and alkoxyl radicals are more abundant than the alkyl peroxyl radicals formed in the propagation stage. This fact together with the more rapid decomposition of hydroperoxides results in formation of polymers with carbon- carbon or carbon-oxygencarbon linkages from the very early stages of heating. A high variety of products of different polarity, stability and molecular weight are formed during the complex process of frying, including triacylglycerol dimers and polymers, oxidized triacylglycerols and volatile compounds. It is well-known that the best methods to evaluate frying degradation are the determination of polar compounds [3] and the determination of polymers [4], which provide the total content of the new compounds formed and the levels of polymers, respectively. Maximum levels of $25 \%$ polar compounds or $16 \%$ polymers have been established as the upper limits of oil degradation for human consumption by most countries adopting regulations on frying fats and oils [5].

Antioxidants naturally occurring in oils and those added to frying oils play a prominent role in their protection against thermal and oxidative deterioration and hence in the manufacture of high quality fried products. Primary or chain-breaking antioxidants mainly act as hydrogen donors, reacting with the alkyl and alkyl-peroxyl radicals. Phenolic compounds including either naturally ocurring tocopherols, tocotrienols and polyphenols or synthetic antioxidants such as butylated hydroxytoluene (BHT), butylated hydroxyanisol (BHA) and tertiary butyl hydroquinone (TBHQ) stand out. Compounds of synergic action, such as citric acid and ascorbyl palmitate, are normally metal quelators or regenerators of primary antioxidants. The action of antioxidants is well known under room temperature conditions during storage or at the moderate temperatures of accelerated tests used to measure oil stability. However, under frying conditions, involving oxidative and thermal reactions, evaluation of antioxidant efficacy is far more complicated [1, 6-12].

This review is focused on the analysis and evaluation of efficacy of antioxidants in frying. Specific aspects of the action of natural and synthetic antioxidants at high 
temperature are discussed, and the most important methods used for the analysis of antioxidants acting in frying and the evaluation of their efficacy are described.

\section{ANTIOXIDANTS IN FRYING}

In this section, the main antioxidants in frying oils either naturally occurring or added to improve the oil stability are described. Two groups can be differentiated, i.e., natural and synthetic antioxidants.

\subsection{Natural antioxidants}

\subsubsection{Tocochromanols (tocopherols and tocotrienols)}

Tocochromanols or, more generally, vitamin E, represent a family of natural, structurally related compounds known as tocopherols and tocotrienols. Tocopherols are the main naturally occurring antioxidants in edible oils and are also used as additives in frying oils to improve their oxidative stability. In Europe, $\alpha$-, $\gamma$ - and $\delta$-tocopherol are used as additives, coded E307, E308 and E309, respectively, and a tocopherol-rich mixture is also permitted as additive (E306) [13].

A mechanism dependent on temperature seems to be involved in tocopherols action [14] since the loss of tocopherol under frying conditions is, in general, relatively to oil degradation, more rapid as the degree of oil unsaturation decreases [15-19], while the opposite is found at lower temperatures, from ambient temperatures up to $100^{\circ} \mathrm{C}[20$, 21]. Therefore accelerated tests at moderate temperatures or under the conditions of the Rancimat test may be useful to predict the relative oxidation behavior of different oils and fats, but not indicative of their frying performance.

Additionally, it has been found that the amounts of polymers and polar compounds at the point of tocopherol exhaustion were significantly lower in monounsaturated oils compared to polyunsaturated oils $[17,18,22,23]$. These results have been reported in different studies either in model systems [24] or oils [25, 26]. Since monounsaturated oils become unprotected at levels of polar compounds much lower than the limit established in official regulations, products fried in monounsaturated oils may be more susceptible to oxidation during storage [27].

Figure 1 reflects the different behavior of tocopherols at frying temperature in conventional or high-linoleic (HLSO) and high-oleic sunflower oil (HOSO) with similar 
tocopherol content and composition, constituting $\alpha$-tocopherol more than $95 \%$ of total tocopherol [23]. Apart from the expected higher polymerization of the tocopherolstripped oils as compared to their counterparts, the most important finding was that not only the loss of tocopherols was more rapid in the less unsaturated oil (HOSO), but also tocopherols were exhausted at lower oil degradation. It has been reported that tocopherols have a very low volatility at frying temperature and hence their rapid loss is due to their degradation. In this respect, the formation of $\gamma$-tocopherolquinone, $4 \gamma, 5$ epoxy- $\gamma$-tocopherolquinone, and 7,8-epoxy- $\gamma$-tocopherolquinone has been demonstrated and their antioxidant efficacy has been suggested [24].

Concerning the type of tocopherol, it has been shown that $\alpha$-tocopherol is less stable at high temperature than $\delta$-tocopherol, while $\beta$ - and $\gamma$-tocopherols degrade at an intermediate rate [23, 28-31]. As a result, new sunflower lines have been developed to increase levels of $\gamma$-tocopherol and decrease the relative content of linolenic acid [32, 33]. In particular, a sunflower oil from a line of seeds characterized by increased levels of both palmitic acid and oleic acid and a modified tocopherol profile made up of $\gamma$ tocopherol (>95\% of total tocopherols) has been found highly stable [34].

With respect to tocotrienols, their action is still poorly known. In general, the stability of $\alpha$-tocotrienol was found to be similar to that of $\alpha$-tocopherol [35, 36], while the order of stability of the different tocotrienol homologues was different from that of their tocopherol counterparts, being $\gamma$-tocotrienol the least stable [36].

Analysis of tocopherols and tocotrienols is standardized [37] and approached in frying oils or oils extracted from fried products by direct normal-phase HPLC with fluorescence detector. The method allows separation of the individual tocopherols and tocotrienols ( $\alpha, \beta, \gamma$ and $\delta$ ). Calibration factors are determined for each tocopherol type using solutions of standard tocopherols while those for tocotrienols are taken to be equivalent to those of the corresponding tocopherols.

\subsubsection{Polyphenols}

The main group of polyphenols showing protective action during frying is present in virgin olive oil and mainly comprises hydroxytyrosol, tyrosol and their derivatives, and lignans [38]. The other two groups of polyphenols of reported antioxidant effect in frying are $\gamma$-oryzanol, i.e. sterol esters of ferulic acid, in bran rice oil [39], and lignans, 
namely sesamol, sesaminol, sesamolin and others in sesame oil [40,41]. Interestingly, studies analyzing the losses of tocopherols and polyphenols during frying report a high rate of degradation for hydroxytyrosol and its derivatives, a similar or lower rate for $\alpha$ tocopherol and a low degradation rate for tyrosol, its derivatives and lignans [42-46]. The rapid loss of hydroxytyrosol suggests a substrate-independent degradation as a more important reaction than its antioxidant effect. Hence, the effective protection found is probably more related to the group of less active antioxidants present, i.e., lignans and tyrosol and its derivatives, which remain longer at frying temperatures.

There have been few reports on the good frying performance of sesame and rice bran oil. Most of such studies, however, have shown a significant increase in the oil thermostability and a higher retention of natural tocopherols in blends of different oils with either sesame or rice bran oil [47-52]. In sesame oil, neither sesamin for sesamolin have shown appreciable antioxidant activity, but the latter may be hydrolyzed during frying yielding sesamol and sesaminol, both showing high stability and synergic effect with tocopherols [53].

Some ingredients based on extracts rich in polyphenols obtained from oils or their byproducts have been commercialized [54, 56]. Besides improving thermostability of oils during frying, addition of these natural products to oils is aimed at increasing the antioxidants intake [57-63]. Also, the addition of individual flavonoids, i.e., pelargonidin, cyanidin, quercetin and myrecetin, has been shown to be very effective in increasing oil thermostability [64].

Numerous methods based on extraction and analysis by high-performance liquid chromatography are used for analysis of polyphenols, but none of them has been standardized [65]. In the last few years, the development of chromatographic columns packed with sub- $2 \mu \mathrm{m}$ particles and the modern high resolution mass spectrometry (MS) have opened up new possibilities and emerged as an ideal tool for profiling complex samples due to its speed, efficiency, sensitivity and selectivity. Recently, Motilva and coworkers have addressed improvements achieved by the use of ultra-high performance liquid chromatography (UHPLC), coupled to MS or tandem MS (MS/MS) as the detector system, in an excellent review [66]. Additionally, the different strategies used to extract the polyphenolic fraction prior to chromatographic analysis were reviewed. The extraction of polyphenols from oils is based on solid-phase extraction (Diol or C18 cartridges), the non-polar fraction of the oil is first removed with hexane and then the 
polyphenol fraction is eluted with methanol $[67,68]$. In oils, C18 columns are used as stationary phase for UHPLC analysis.

\subsubsection{Phytosterols}

4-Desmethylsterols and 4-methylsterols with an ethylidene group in the side chain like $\Delta 5$-avenasterol, $\Delta 7$-avenasterol, fucosterol, vernosterol and citrostadienol as well as their esters have been found to contribute to delaying oil degradation at frying temperature [7, 69, 70], but some authors have reported non-existent or slight effect [7173]. They are normally referred as to antipolymerization agents even though they seem to act as antioxidants, i.e., through formation of allyl radicals in a primary carbon atom followed by isomerization to a relatively stable tertiary radical [70].

Determination of phytosterols in oils is standardarized [74] and consists basically of gas chromatography analysis of the unsaponifiable fraction.

\subsubsection{Squalene}

Squalene is a highly unsaturated hydrocarbon with important health effects, present in large quantities in shark liver oil and in small amounts in olive oil and wheat germ oil. Although there is rather scant information on squalene efficacy at frying temperatures, it seems to show only low or moderate effect $[75,76]$.

The different methods used to analyze squalene have been recently reviewed [77], including basically a preliminary treatment with $\mathrm{KOH}$ containing ethanol at $90^{\circ} \mathrm{C}$ for saponification, extraction of the unsaponifiable fraction with hexane, and HPLC analysis using C8 or C18 chromatographic columns, organic mobile phases based on acetonitrile/acetone mixtures, and UV detection. The authors strongly recommend addition of octadecylbenzene as an internal standard instead of squalene for external calibration.

\subsubsection{Plant extracts}

In the last decade, a significant number of studies focused on the positive effects of the addition of plant extracts, mainly herbs and spices, to frying oils have been published [12], following the studies on their antioxidative properties at room temperature [78, 79]. The addition of plant extracts is directed not only to delay the oil deterioration by 
protecting the natural antioxidants, i.e. tocopherols, but also to increase the consumption of natural, healthy compounds in response to consumers demand.

Extracts of rosemary [28, 80-84], tea [85], sage [82, 86], oregano [87, 88], lavender and thyme [89], summer savory [84], carob fruit [90], Curcuma [91] and others [92, 93] are some examples of the high number of reports on the subject.

In general, the action found is positive because the extracts contain potent antioxidants, which are detailed in an excellent review on the most important herbs and spices [78]. However, the protective effect during frying is highly variable even for the same extract because of the inherent characteristics of natural products, joined to the complexity of the frying process. Unfortunately, the composition of an extract is often poorly defined and varies greatly depending on the plant variety, extraction method and concentration added. When studies include characterization of extracts, it is usually based on the analysis of polyphenols $[65,66]$ but the antioxidative action may also depend on the content and chemical structure of other minor compounds present exerting a prooxidant or antioxidative action.

\subsection{Synthetic antioxidants}

\subsubsection{Dimethylpolysiloxane}

Dimethylpolysiloxane (DMPS) is the most important additive in frying (coded as E900), normally added at very low concentrations (1-2 mg/kg). The first studies showed that DMPS acted as an antioxidant when samples were thermostatically heated in a fryer, as they deteriorated slower than the control without the additive. The reverse was found when the oils were heated at the same temperature in an oven [94]. In the study of Freeman et al. [95], experiments were carried out by heating the samples on a hot plate or in a fryer and a tremendous enhancement of oil thermostability was obtained after addition of DMPS. The minimum amount which exerted a protective action corresponded to that forming a monolayer on the oil surface, as stated by decreasing the amount of DMPS until its action disappeared. The authors hypothesized different possibilities for the precise mechanisms of action of this monolayer. The monolayer may form a barrier preventing the entrance of air or, more probably, the oxidation takes place at the oil - air interface and DMPS provides a relatively inert surface. Alternatively, it was proposed that DMPS may inhibit the convention currents in the surface thus impeding the entrance of oxygen. 
Further studies were focused on the influence of DMPS addition and the main variables in frying, i.e. temperature, length of time, surface-to-oil volume ratio and type of heating. The statistical analysis indicated the strong interaction between the presence of DMPS and the type of heating and the influence of the surface-to-volume ratio [17]. Later experiments were carried out on discontinuous and continuous laboratory frying [18], as well as in industrial continuous frying [96], which confirmed the results under practical conditions.

Figure 2 illustrates the great differences of DMPS effectiveness between discontinuous (A) and industrial continuous (B) frying of potatoes in two sunflower oils of different degree of unsaturation, i.e. high-oleic and high-linoleic sunflower oils. Results obtained for polar compounds showed that DMPS was highly effective in discontinuous frying, supporting that oil degradation occurred mainly when the food was not present and the surface was unprotected from the penetration of oxygen. Quite in contrast, DMPS exerted no appreciable protective action in simulated continuous frying. Hence addition of DMPS would not be necessary in industrial frying since the oil surface is disturbed, but well protected by steam water from the fried food. On the contrary, addition of DMPS was highly positive in discontinuous frying being specifically active during the period in which the oil is not protected by steam water from the fried food. Therefore, DMPS is recommended in fried food establishments where the oil in the fryer usually remain at elevated temperatures during significant periods of times without food, i.e. catering services, fast-food outlets, restaurants and others [97].

According to AOCS methods, analysis of DMPS in oils is carried out by a direct aspiration, flame atomic absorption method [98].

\subsubsection{Ascorbyl palmitate}

Ascorbyl palmitate is a lipophilic derivative of ascorbic acid that acts mainly as an oxygen quencher and a reducing agent or heavy metal ions. The effect of ascorbyl palmitate at frying temperatures is not clear. When used as an additive (coded E304), no significant effect was found in some studies [99, 100] while, in others, a delay in the formation of degradation compounds [80, 101-103] and increased stability of tocopherols [80] have been reported.

Ascorbyl palmitate is normally extracted from oils with methanol and analyzed by HPLC [104], but the main drawback is its stabilization during separation. Perrin and Meyer proposed a procedure under conditions preventing the degradation of ascorbyl 
palmitate, through the use of citric acid in combination with isoascorbic acid for its stabilization in standard and sample solutions and for inactivation of oxidizing agents in the HPLC system [105].

\subsubsection{Synthetic phenolic antioxidants}

Butylated hydroxyanisol (BHA), butylated hydroxytoluene (BHT), propyl gallate (PG), and tertiary butyl hydroquinone (TBHQ) have been traditionally added to fats and oils to extend effectively their shelf life, but their effectiveness at frying temperatures is lower due to their rapid volatilization and decomposition. BHT and TBHQ have shown the highest volatility, while PG was the least volatile at frying temperatures. With regard to their comparative stability against thermal oxidation the order found was BHT $>$ PG > BHA > TBHQ [106]. The decomposition products were also studied and mainly dimeric compounds were found from BHA and BHT. From TBHQ, tertiary butyl benzoquinone (TBBQ) was detected as the major degradation product along with many dimeric compounds with ether linkages, some of them with residual antioxidant activity.

TBHQ has been reported to be more effective than BHA and BHT [80, 107]. Interestingly, in the study testing the effect of BHT, BHA, PG and TBHQ and their binary and tertiary mixtures with synergists and tocopherols, it was found that the interaction between antioxidants at high temperature could lead to a negative or positive synergism. Also, as already remarked in this review, the protection conferred by antioxidants was quite different at frying and at low temperatures [107]. Novel antioxidants derived from TBHQ but with higher solubility, i.e., lauryl TBHQ and lauryl TBBQ, have been found to exert stronger antioxidant activity than TBHQ at temperatures higher than $140{ }^{\circ} \mathrm{C}[108]$.

In Europe, the use of BHA, BHT, TBHQ, propyl gallate, octyl gallate and docedyl gallate as additives is regulated [13], and their codes are E320, E321, E310, E311 and E312, respectively. BHA is permitted in oils and fats individually or combined with propyl gallate, octyl gallate, dodecyl gallate and TBHQ.

BHA, BHT, TBHQ and gallates are determined routinely after double extraction with methanol followed by HPLC analysis according to official methods [109-111]. Recoveries higher than 90\% are obtained for all antioxidants except for BHT (86-90\%). 


\subsubsection{Citric acid-based antioxidant}

Citric acid lacks effect during frying because it volatilizes at temperatures above $150{ }^{\circ} \mathrm{C}$ [81]. However, an additive prepared with citric acid with potassium sulphate and aluminum silicate as adyuvants has been found effective in frying [112, 113]. It is formulated using energy potential technology, which modulates active energy charges and the electron transport chain to boost citric acid's antioxidant properties without thermal or chemical treatment.

\section{Evaluation of antioxidant efficacy in frying}

Antioxidants efficacy is widely measured in foods, plant extracts and biological samples through several methods using radical generating systems, such as the DPPH, TEAC or ABTS, TRAP or ORAC assays [8]. In oils, testing the action of antioxidants requires design of assays under shelf-life conditions or under accelerated conditions by means of increasing temperature and/or air availability. The Oil Stability Index is a standard method normally used to determine the oxidative susceptibility of oils and antioxidant efficacy at $100^{\circ} \mathrm{C}$ with bubbling air [114].

Testing the action of antioxidants during frying, which differs greatly from that shown at shelf-life or moderate temperatures, is approached by simulating the real conditions of frying in the absence or presence of food.

In the absence of food, application of standard conditions is essential to make comparable the results obtained for antioxidant efficiency. This mainly involves definition of temperature, length of time and surface-to-volume ratio. Also, selection of standard methods of proved validity to determine the main degradation compounds formed in frying, i.e., polar compounds and polymer determinations [9] is crucial. Still, highly variable values are often obtained in thermoxidation experiments, depending on the conditions applied [17].

In real deep-frying operations, there are important differences between industrial, continuous frying, and discontinuous frying. In the former, protection of the surface by the food, always present in the fryer, and replenishment of food-absorbed oil with unused oil contribute to maintaining the oil quality. However, discontinuous frying is characterized by heating-cooling cycles, between which the oil remains at high temperature without being protected by the food, and oil replenishment is normally not applied. The latter process leads to the highest levels of oil degradation in used frying 
oils and fried foods [115] and is normally simulated by tedious experiments consisting of $10-20^{\text {th }}$ frying operations using potatoes, with around 30 min-intervals between frying operations.

A standard procedure was proposed to evaluate the performance of fats and oils and antioxidant efficiency at frying temperatures using the heating block of a Rancimat and the standard Rancimat vessels. Temperature homogeneity in all vessels in the heating block is readily attained. This procedure simulates the usual conditions of the main variables of the discontinuous frying process, namely, temperature, surface-to-oil volume ratio and presence of air [116]. The values used for the variables were carefully selected: $180^{\circ} \mathrm{C}$, the temperature most representative of the frying procedure; length of heating decided as to achieve polar compounds or polymers levels close to those normally found, setting the maximum alteration levels according to limitations established [5]; complete introduction of the sample in the heating block to ensure homogeneous heating;; and sample amount (8 g) as to achieve a surface-to-oil volume ratio $\left(0.4 \mathrm{~cm}^{-1}\right)$ similar to that found in small domestic fryers [18].

Table 1 lists some results obtained for HLSO and HOSO with similar tocopherol contents after $6 \mathrm{~h}$ laboratory discontinuous frying of potatoes [18] and thermoxidation in a Rancimat following the proposed method for simulated frying [116]. Also, values obtained recently for virgin olive oil and virgin avocado oil following the same procedures have been included (unpublished data). Repeatability was very good as the evaluation of samples in triplicate gave coefficients of variation $<5 \%$ for polymers and $<6 \%$ for polar compounds. Results were very similar after 10 -h simulated frying in Rancimat and 6-h total frying time in discontinuous frying, and showed higher values for HLSO and AO as compared to HOSO and OO. OSI value was clearly not indicative of behavior of oils in frying since, for example, OO had five-fold higher stability than HOSO.

Other procedure later proposed to evaluate frying performance of oils consisted in heating $20 \mathrm{~g}$ of sample supplemented with $1 \mathrm{~g}$ of silica gel containing $10 \%$ water in a standard vessel at $170{ }^{\circ} \mathrm{C}$ for $2 \mathrm{~h}$. After quantification of polymers, results are expressed as 100 /polymer (\%).The method was applied to different oils and a good correlation with sensory data was found [117]. 


\section{Final remarks}

a) The action of antioxidants at frying temperatures cannot be deduced from their behaviour at low or moderate temperatures.

b) Application of antioxidants at the high temperature of frying requires special considerations, especially those based on antioxidant stability and volatility.

c) Experiments designed to test antioxidant efficacy should reflect closely real frying conditions, involving mainly careful selection of temperature, length of heating time and surface-to-oil volume ratio. Also, to evaluate the oil deterioration and hence the antioxidants efficacy, standard methods of proved validity (polar compounds or polymer determinations) should be applied.

d) Much analytical research is needed on antioxidants identification and quantification to advance on the development of standardized methods, with special emphasis on the multitude of compounds constituting the pool of polyphenols present in plant extracts. 


\section{References}

[1] Choe, E., Min, D.B., Chemistry of deep-fat frying oils’. J. Food Sci., 2007, 72, R77R86.

[2] Dobarganes, M.C., Márquez-Ruiz, G., Formation and analysis of oxidized monomeric, dimeric and higher oligomeric triglycerides', in Erickson M D, Deep Frying: Chemistry Nutrition and Practical Applications. $2^{\text {nd }}$ edition, 2007, Champaign, Illinois, AOCS, 87-110.

[3] IUPAC, Standard method 2.507: Determination of polar compounds in frying fats, in International Union of Pure and Applied Chemistry, Standard methods for the analysis of oils, fats and derivatives, 7th edition, 1987, Oxford, Blackwell.

[4] IUPAC, Standard method 2.508: Determination of polymerized triglycerides in oils and fats by high performance liquid chromatography, in International Union of Pure and Applied Chemistry, Standard methods for the analysis of oils, fats and derivatives, 1st Supplement to the 7th Edition, 1992, Oxford, Blackwell.

[5] Firestone, D., Regulation of frying fats and oils, in Erickson M D, Deep Frying: Chemistry Nutrition and Practical Applications. $2^{\text {nd }}$ edition, 2007, Champaign, Illinois, AOCS, 373-385.

[6] Boskou, D., Frying temperatures and minor constituents of oils and fats. Grasas y Aceites 1998, 49, 326-330.

[7] Velasco, J., Dobarganes, M.C., Oxidative stability of virgin olive oil. Eur. J. Lipid Sci. Technol. 2002, 104, 661-676.

[8] Warner, K., Su, C., White, P., Role of antioxidants and polymerization inhibitors in protecting frying oil, in Gupta M K, Warner K and White P J, Frying: Technologies and Practices, Champaign, Illinois, AOCS, 2004, 37-49.

[9] Frankel, E.N., Antioxidants in Food and Biology: Facts and Fiction. Bridgwater, England, The Oily Press, 2007.

[10] Márquez-Ruiz, G., Ruiz-Méndez, M.V., Velasco, J., Dobarganes, M.C., Preventing oxidation during frying of foods, in Decker E, Oxidation in Foods and Beverages and Antioxidant Applications, Cambridge, United Kingdom, Woodhead Publishing Limited, 2010, 239-273.

[11] Marmesat, S., Morales, A., Velasco, J., Dobarganes, M.C., Action and fate of natural and synthetic antioxidants during frying. Grasas y Aceites 2010, 61, 333-340.

[12] Wagner, K.H., Elmadfa, I., Nutrient antioxidants and stability of frying oils (tocochromanols, Ecarotene, phylloquinone, ubiquinone 50 and ascorbyl palmitate), in Boskou D, Elmadfa I, Frying of food, $2^{\text {nd }}$ Ed., Boca Raton, FL, USA, CRC Press, 2011, 178-197.

[13] Boskou D., Nonnutrient antioxidants and stability of frying oil, in Boskou D, Elmadfa I, Frying of food, $2^{\text {nd }}$ Ed., Boca Raton, FL, USA, CRC Press, 2011, 199-223.

[14] Commission Regulation (EU) No 1129/2011 of 11 November 2011 amending Annex II to Regulation (EC) No 1333/2008 of the European Parliament and of the 
Council by establishing a Union list of food additives, Off. J. Eur. Commun. L295, Vol. 54, 1, November 2011.

[15] Marinova, E.M., Yanishlieva N.V., Effect of temperature on the antioxidative action of inhibitors in lipid autoxidation. J Sci Food Agric, 1992, 60, 313-318.

[16] Simmone, A.H., Eitenmiller, R.R., Retention of vitamin E and added retinyl palmitate in selected vegetable oils during deep-fat frying and in fried breaded products. J. Agr. Food Chem. 1998, 46, 5273-5277.

[17] Jorge, N., Márquez-Ruiz, G., Martín Polvillo, M., Ruiz-Méndez, M.V., Dobarganes, M.C., Influence of dimethylpolysiloxane addition to edible oils: dependence on the main variables of the frying process. Grasas Aceites. 1996, 47, 1419.

[18] Jorge, N., Márquez-Ruiz, G., Martín Polvillo, M., Ruiz-Méndez, M.V., Dobarganes, M.C., Influence of dimethylpolysiloxane addition to frying oils: Performance of sunflower oils in discontinuous and continuous laboratory frying. Grasas Aceites. 1996, 47, 20-25.

[19] Wagner, K.H., Wotruba, F., Elmadfa, I., Antioxidative potencial of tocotrienols and tocopherols in coconut fat at a different oxidation temperatures. Eur. J. Lipid Sci. Technol. 2001, 103, 746-751.

[20] Martín-Polvillo, M., Márquez-Ruiz, G., Dobarganes M.C., Oxidative stability of sunflower oils differing in unsaturation degree during long-term storage at room temperature', J. Am. Oil Chem. Soc., 2004, 81, 577-583.

[21] Márquez-Ruiz, G., Martín-Polvillo M., Velasco J., Dobarganes M.C., Formation of oxidation compounds in olive and sunflower oils under oxidative stability index (OSI) conditions. Eur. J. Lipid Sci. Technol, 2008, 110, 465-471.

[22] Barrera-Arellano, D., Ruiz-Méndez, M.V., Márquez-Ruiz, G., Dobarganes, M.C., Loss of tocopherols and formation of degradation compounds in triacylglycerol model systems heated at high temperature. J. Sci. Food Agr. 1999, 79, 1923-1928.

[23] Barrera-Arellano, D., Ruiz-Méndez, M.V., Velasco, J., Márquez-Ruiz, G., Dobarganes, M.C., Loss of tocopherols and formation of degradation compounds at frying temperatures in oils differing in unsaturation degree and natural antioxidant content. J. Sci. Food Agr. 2002, 82, 1696-1702.

[24] Verleyen, T., Kamal-Eldin, A., Dobarganes, M.C., Verhe, R., et al. Modeling of $\alpha$ tocopherol loss and oxidation products formed during thermoxidation in triolein and tripalmitin mixtures. Lipids 2001,36, 719-726.

[25] Normand, L., Eskin, N. A.M., Przybyslki, R., Comparison of the stability of regular and high-oleic sunflower oils. J. Am. Oil Chem. Soc. 2001, 84, 331-334.

[26] Verleyen, T., Kamal-Eldin, A., Mozuraityte, R., Verhé, R. et al. Oxidation at elevated temperatures: competition between $\square$ tocopherol and unsaturated triacylglycerols. Eur. J. Lipid Sci. Technol. 2002, 104, 228-233.

[27] Márquez-Ruiz, G., Martín-Polvillo, M., Jorge, N., Ruiz Méndez, M. V., Dobarganes, M. C., Influence of used frying oil quality and natural tocopherol content on oxidative stability of fried potatoes. J. Am. Oil Chem. Soc. 1999, 76, 421-425. 
[28] Gordon, M. H., Kourimska, L., Effect of antioxidants on losses of tocopherols during deep-fat frying. Food Chem. 1995a, 52, 175-177.

[29] Lampi, A., Kamal-Eldin, A., Effect of $\alpha$-and $\gamma$ tocopherols on thermal polymerization of purified high-oleic sunflower triacylglycerols. J. Am. Oil Chem. Soc. 1998, 75, 1699-1703.

[30] Warner, K., Moser, J., Frying Stability of Purified Mid-Oleic Sunflower Oil Triacylglycerols with Added Pure Tocopherols and Tocopherol Mixtures. J. Am. Oil Chem. Soc., 2009, 86, 1199-1207.

[31] Aladedunye, F., Przybylski, R., Frying stability of high oleic sunflower oils as affected by composition of tocopherol isomers and linoleic acid content. Food Chem. 2013, 2373-2378.

[32] Demurin, Y., Škorić, D., Karlovic, D., Genetic variability of tocopherol composition in sunflower seeds as a basis of breeding for improved oil quality. Plant Breed. 1996, 115, 33-36.

[33] Velasco, L., Domínguez, J., Fernández-Martínez, J.M., Registration of T589 and T2100 sunflower germplasms with modified tocopherol profiles. Crop Sci. 2004, 44, 361-362.

[34] Marmesat, S., Velasco, L., Ruiz-Méndez, M. V., Fernández-Martínez, J. M., Dobarganes, M. C., Thermostability of genetically modified sunflower oils differing in fatty acid and tocopherol compositions. Eur. J. Lipid Sci. Technol. 2008, 110, 776-782.

[35] Romero, N., Robert, P., Masson, L., Ortiz, J., et al. Effect of $\alpha$-Tocopherol and $\alpha-$ Tocotrienol on the performance of Chilean Hazelnut Oil (Gevuina avellana mol) at high temperature. J. Sci. Food Agric. 2004, 84, 943-948.

[36] Romero, N., Robert, P., Masson, L., Ortiz, J., et al. Effect of $\alpha$-tocopherol, $\alpha$ tocotrienol and Rosa mosqueta shell extract on the performance of antioxidant-stripped canola oil (brassica sp) at high temperature. Food Chem. 2007, 104, 383-389.

[37] Rossi, M., Alamprese, C., Ratti, S., Tocopherols and tocotrienols as free radicalscavengers in refined vegetable oils and their stability during deep-fat frying. Food Chem. 2007, 102, 812-817.

[38] IUPAC, Standard method 2.432: Determination of tocopherols and tocotrienols in vegetable oils and fats by high performance liquid chromatography, in International Union of Pure and Applied Chemistry, Standard methods for the analysis of oils, fats and derivatives, 1st Supplement to the 7th Edition, 1992, Oxford, Blackwell.

[39] Bendini, A., Cerretani, L., Carrasco-Pancorbo, A., Gomez-Caravaca, A., et al. Phenolic molecules in virgin olive oils: a survey of their sensory properties, health effects, antioxidant activity and analytical methods. An overview of the last decade. Molecules, 2007, 12, 1679-1719.

[40] Lerma-Garcia, M. J., Herrero-Martinez, J. M., Simo-Alfonso, E. F., Mendonca, C. R. B., Ramis-Ramos, G., Composition, industrial processing and applications of rice bran gamma-oryzanol. Food Chem. 2009, 115, 389-404.

[41] Moazzami, A. A., Haese, S.L., Kamal-Eldin, A., Lignan contents in sesame seeds and products. Eur. J. Lipid Sci. Technol. 2007, 109, 1022-1027. 
[42] Andrikopoulos, N.K., Dedoussis, G.V.Z., Falirea, A. Kalogeropoulos, N., Hatzinikola, H.S., Deterioration of natural antioxidant species of vegetable edible oils during the domestic deep-frying and pan-frying of potatoes. Int. J. Food Sci. Nutr. 2002, 53, 351-363.

[43] Brenes, M., García, A., Dobarganes, M. C., Velasco, J. Romero, C. Influence of termal treatments simulating cooking processes on the polyphenol content of virgin olive oil. J. Agric. Food Chem. 2002, 50, 5962-5967.

[44] Gomez-Alonso, S., Fregapane, G, Salvador, M. D., Gordon, M.H., Changes in phenolic composition and antioxidant activity of virgin olive oil during frying. J. Agr. Food Chem. 2003, 51, 667-672.

[45] Nissiotis, M., Tasioula-Margari, M., Changes in antioxidant concentration of virgin olive oil during thermal oxidation. Food Chem., 2003, 77, 371-376.

[47] Daskalaki, D., Kefi, G., Kotsiou, K., Tasioula-Margari, M., Evaluation of phenolic compound degradation in virgin olive oil during storage and heating. J. Food Nutr. Res. 2009, 48, 31-41.

[48] Chung, J., Lee, Y., Choe, E., Oxidative stability of soybean and sesame oil mixtures during frying of flour dough. J. Food Sci. 2006, 71, C222-C226.

[49] Sharma, H. K., Kaur, B., Sarkar, B. C., Singh, C., Thermal behaviour of pure rice bran oil, sunflower oil and their model blends during deep fat frying. Grasas Aceites 2006, 57, 376-381.

[50] Shing, A., Sharme, H. K., Sarkar, B. C., Singh, C., Shitandi, A. A., Thermal behaviour of pure rice bran oil, safflower oil and their model blends during deep fat frying. J. Food Sci. Technol. 2007, 44, 52-55.

[51] Khan, M. I., Asha, M. R., Bhat, K. K., Khatoo, S., Studies on quality of coconut oils blends after frying potato chips. J. Am. Oil Chem. Soc. 2008, 85, 1165-1172.

[52] Farhoosh, R., Kenary, R. E., Anti-rancidity effects of sesame and rice bran oils on canola oil during deep frying. J. Am. Oil Chem. Soc. 2009, 86, 539-544.

[53] Krishna, A. G. G., Khatoon, S., Babylatha, R., Frying performance of processed rice bran oils. J. Food Lipids. 2005, 12, 1-11.

[54] Kochhar, S. P., Stabilization of frying oils with natural antioxidative components. Eur. J. Lipid Sci. Technol. 2000, 102, 552-559.

[55] Kochhar, S. P., The composition of frying oils, in Rossell J B, Frying. Improving Quality, Lancaster, Woodhead, 2001, 87-114.

[56] Gertz, C., Optimising the baking and frying process using oil-improving agents. Eur. J. Lipid Sci. Technol. 2004, 106, 736-745.

[57] Nasirullah, Rangaswamy, B. L., Oxidative stability of healthful frying oil medium and uptake of inherent nutraceuticals during deep frying. J. Am. Oil Chem. Soc. 2005, 82, 753-757.

[58] Farag, R. S., Mahmoud, E. A., Basuni, A. M., Use crude olive leaf juice as a natural antioxidant for the stability of sunflower oil during heating. Int.J. Food Sci. Technol. 2007, 42, 107-115. 
[59] Hemalatha, S., Ghafoorunissa, Sesame Lignans enhance the thermal stability of edible vegetable oils. Food Chem. 2007,105, 1076-1085.

[60] Lee, J., Lee, Y., Choe, E., Effect of sesamol, sesamin and sesamolin extracted from roasted sesame oil on the thermal oxidation of methyl linoleate. LWT-Food Sci. Technol. 2008, 41, 1871-1875.

[61] Chiou, A., Kalogeropoulos, N., Salta, F. N., Efstathiou, P., Andrikopoulos, N. K., Pan-frying of French fries in three different edible oils enriched with olive leaf extract: Oxidative stability and fate of microconstituents. LWT-Food Sci. Technol. 2009, 42, 1090-1097.

[62] Inanc, T., Medeni, M., Testing the Antioxidant Effect of Essential Oils and BHT on Corn Oil at Frying Temperatures: a Response Surface Methodology. J. Am. Oil Chem. Soc. 2013, 90, 1845-1850.

[63] Misnawi, T., Susijahadi, W., Eka, N.D., Noor, A.F., The utilization of cocoa polyphenol extract to improve the shelf life of bulk frying oil used in open and deep frying. Int. Food Res. J. 2014, 21, 111-118.

[64] Naz, S., Siddiqi, R., Sayeed, S. A. Effect of flavonoids on the oxidative stability of corn oil during deep frying. Int. J. Food Sci. Nutr. 2008, 43, 1850-1854.

[65] Ajila, C. M., Brar, S. K.,Verma, M.,Tyagi, R. D.,Godbout, S.,Valero, J. R. Extraction and analysis of polyphenols: Recent trends. Crit. Rev. Biotechnol. 2011, 227249.

[66] Moltiva, M.J., Serra, A., Maciá, A., Analysis of food polyphenols by ultra highperformance liquid chromatography coupled to mass spectrometry: An overview. $J$. Chromatogr. A 2013, 1292, 66-82

[67] Suárez, M., Macià, A., Romero, M.P., Motilva, M.J., Improved liquid chromatography tandem mass spectrometry method for the determination of phenolic compounds in virgin olive oil. J. Chromatog. 2008, 2214, 90-99

[68] Alarcón-Flores, M.I., Romero-González, R., Garrido A., Frenich, Martínez Vidal J.L., Analysis of phenolic compounds in olive oil by solid-phase extraction and ultra high performance liquid chromatography-tandem mass spectrometry, Food Chem. 2012, 134, 2465-2472

[69] Boskou, D., Morton, I. D., Effect of plant sterols on the rate of deterioration of heated fats. J. Sci. Food Agr. 1976, 27, 928-932.

[70] Gordon, M. H., Magos, P., The effects of sterols on the oxidation of edible oils. Food Chem. 1983, 10, 141-147.

[71] Lampi, A., Dimberg, L. H., Kamal-Eldin, A., A study on the influence of fucosterol on thermal polymerisation of purified high oleic sunflower triacylglycerols. J. Sci. Food Agr. 1999, 79, 573-579.

[72] Winkler, J. K., Warner, K., The effect of phytosterol structure on thermal polymerization of heated soybean oil. Eur. J. Lipid Sci. Technol. 2008a, 110, 10681077. 
[73] Winkler, J. K., Warner, K., The effect of phytosterol concentration on oxidative stability and thermal polymerization of heated oils. Eur. J. Lipid Sci. Technol. 2008b, 110, 455-464.

[74] IUPAC, Standard method 2.403 Identification and determination of sterols by gas-liquid chromatography, in International Union of Pure and Applied Chemistry, Standard methods for the analysis of oils, fats and derivatives, 1st Supplement to the 7th Edition, 1992, Oxford, Blackwell.

[75] Sims, R. J., Fioriti, J. A., Kanuk, M.J., Sterol additives as polymerization inhibitors for frying oils. J. Am. Oil Chem. Soc. 1972, 49, 298-301.

[76] Malecka, M., The effect of squalene on the thermostability of rapeseed oil. Food Nahrung, 2006, 38, 135-140.

[77] Matsuura, H., Watanabe, M.M., Kaya, K, Squalene quantification using octadecylbenzene as the internal standard, Procedia Environ. Sci. 2012, 15, 43 --46.

[78] Yanishlieva, N. V., Marinova, E., Stabilization of edible oils with natural antioxidants. Eur. J. Lipid Sci. Technol. 2001, 103, 752-767.

[79] Yanishlieva, N. V., Marinova, E., Pokorny, J., Natural antioxidants from herbs and spices. Eur. J. Lipid Sci. Technol. 2006, 108, 776-793.

[80] Gordon, M. H., Kourimska, L., The effects of antioxidants on changes in oils during heating and deep frying. J. Sci. Food Agric. 1995b, 68,347-353.

[81] Jaswir, I., Man, Y. B. C., Use optimization of natural antioxidants in refined, bleached, and deodorized palm olein during repeated deep-fat frying using response surface methodology. J. Am. Oil Chem. Soc. 1999, 76, 341-348.

[82] Man, Y. B. C., Tan, C. P., Effect of natural and synthetic antioxidants in refined, bleached, and deodorized palm olein during repeated deep-fat frying of potato chips. $J$. Am. Oil Chem. Soc. 1999, 76, 331-339.

[83] Lalas, S., Dourtoglou, V., Use of rosemary extract in preventing oxidation during deep-fat frying of potato chips. J. Am. Oil Chem. Soc. 2003, 80, 579-583.

[84] Kalantzakis, G., Blekas, G., Effects of Greek sage and summer savory extracts on vegetable oil thermal stability. Eur. J. Lipid Sci. Technol. 2006, 108, 842-847.

[85] Naz, S., Sheikh, H., Siddiqi, R., Sayeed, S. A., Oxidative stability of olive, corn and soybean oil under different conditions. Food Chem. 2004, 88, 253-259.

[86] Jaswir, I., Kitts, D.D., Che Man, Y., Hassan, T., Synergistic effect of rosemary, sage and citric acid fatty acid retention of palm olein during deep frying. J. Am. Oil Chem. Soc. 2006, 77, 527-533.

[87] Houhoula, D. P., Oreopoulou, V., Tzia, C., Antioxidant efficiency of oregano during frying and storage of potato chips. J. Sci. Food Agr. 2003, 83, 1499-1503.

[88] Houhoula, D. P., Oreopoulou, V., Tzia, C., Antioxidant efficiency of oregano in frying and storage of fried products. Eur. J. Lipid Sci. Technol. 2004, 106, 746-751. 
[89] Bensmira, M., Jiang, B., Nsabimana, C., Jian, T., Effect of lavender and thyme incorporation in sunflower seed oil on its resistance to frying temperatures. Food Res. Int. 2007, 40, 341-346.

[90] Bodega, D. Z., Bastida, S., Marmesat, S., Pérez-Ollero, L., Ruíz-Roso, B., Sánchez-Muniz, F. J., Carob fruit poliphenols reduce tocopherol loss, triacylglycerol polymerization and oxidation in heated sunflower oil. J. Am. Oil Chem. Soc. 2009, 86, 419-425.

[91] Nor, F. M., Mohamed, S., Idris, N. A., Ismail, R., Antioxidative properties of Curcuma Longa leaf extracts in accelerated oxidation and deep frying studies. J. Am. Oil Chem. Soc. 2008a, 86, 141-147.

[92] Shyamala, B. N., Gupta, S., Lakshmi, A. J., Prakash, J., Leafy vegetable extracts. Antioxidant activity and effect on storage stability of heated oils. Inn. Food Sci. Emerg. Technol. 2005, 6, 239-245.

[93] Nor, F. M., Mohamed, S., Idris, N. A., Ismail, R., Antioxidative properties of Pandanus amaryllifolius leaf extracts in accelerated oxidation and deep frying studies. Food Chem., 2008b, 110, 319-327.

[94] Rock, S., Fisher, L., Roth, H., Silicones in frying fats-Antioxidants or prooxidants?. J. Am. Oil Chem. Soc. 1967, 44, 102A.

[95] Freeman, I. P., Padley, F. B., Sheppard, W. L., Use of silicones in frying oils. J Am. Oil Chem. Soc. 1973, 50, 101-103.

[96] Sebedio, J.L., Dobarganes, M.C., Márquez-Ruiz, G., Wester, I., Christie, W.W., Dobson, G., Zwobada, F., Chardigny, J.M., Industrial production of crisps and prefried French fries using sunflower oils. Grasas Aceites 1996, 47, 5-13.

[97] Márquez-Ruiz, G., Velasco, J., Dobarganes, M.C., Effectiveness of dimethylpolysiloxane during deep frying. Eur J. Lipid Sci. Technol., 2004, 106, 752-758.

[98] AOCS Official Method Cd 24-95: Determination of Dimethylpolysiloxanes in Fats and Oils, in Official Methods and Recommended Practices of the American Oil Chemists’ Society, edited by D. Firestone, AOCS Press, Champaign, 1997.

[99] Augustin, M. A., Chua, C. J., Heng, L. K., Effects of silicone and ascorbyl palmitate on the quality of palm olein used for frying of prawn crackers. J. Sci. Food Agr. 1987, 40, 87-93.

[100] Ibrahim, K., Augustin, M. A., Ong, A. S. H., Effects of ascorbyl palmitate and silicone on frying performance of palm olein. Pertanika 1991, 14, 53-57.

[102] Satyanarayana, A., Giridhar, N., Joshi, G. J., Rao, D. G., Ascorbyl palmitate as an antioxidant for deep fat frying of potato chips in peanut oil. J. Food Lipids 2000, 7, 110.

[103] Onal, B., Ergin, G., Antioxidative effects of alpha-tocopherol and ascorbyl palmitate on thermal oxidation of canola oil. Nahrung 2002, 46, 420-426.

[104] Dieffenbacher, A., Trisconi, J.M., Determination of Ascorbyl Palmitate by HPLC. Trav. Chim. Aliment. Hyg. 1991, 82, 475-486. 
[105] Perrin, C., Meyer, L., Simultaneous determination of ascorbyl palmitate and nine phenolic antioxidnats in vegetable oils and edible fats by HPLC. J. Am. Oil Chem. Soc. 2003, 80, 115-118.

[106] Hammama, A.A., Nawar, W.W., Thermal decomposition of some phenolic antioxidants. J. Agr. Food Chem. 1991, 39, 1063-1069.

[107] Allam, S. S. M., Mohamed, H. M. A., Thermal stability of some commercial natural and synthetic antioxidants and their mixtures. J. Food Lipids 2002, 9, 277-293.

[108] Zhang, C. X., Wu, H., Weng, X. C., Two novel synthetic antioxidants for deep frying oils. Food Chem. 2004, 84, 219-222.

[109] AOCS Official Method Ce 6-86: Antioxidants-Liquid Chromatographic Method, in Official Methods and Recommended Practices of the American Oil Chemists' Society, edited by D. Firestone, AOCS Press, Champaign, 1997.

[110] IUPAC, Standard method 2.642: Determination of Antioxidants by HPLC, in International Union of Pure and Applied Chemistry, Standard methods for the analysis of oils, fats and derivatives, 1st Supplement to the 7th Edition, 1992, Oxford, Blackwell

[111] AOAC Official Method 983.15: Phenolic Antioxidants in Oils, Fats and Butter Oil, Liquid Chromatographic Method, in Official Methods of Analysis of AOAC International, edited by W. Horwitz, Association of Official Analytical Chemists, 2000.

[112] Cerretani, L., Bendini, A., Gehring, M., BonoliCarbognin, M., Semenza, P., Lercker, G., Changes in oxidative status of soybean oil by additins of a new antioxidants during frying. AgroFood Industry Hi-Tech 2008, 19, 41-43.

[113] Warner, K., Gehring, M.M., High-temperature natural antioxidant improves soy oil for frying. Food Chem. 2009, 74, C500-C505.

[114] AOCS Official Method Cd 12-92: Oil Stability Index (OSI), in Official Methods and Recommended Practices of the American Oil Chemists' Society, edited by D. Firestone, AOCS Press, Champaign, 1997.

[115] Dobarganes, M.C., Márquez-Ruiz, G., Oxidised fats in foods. Curr Opin Clin Nutr Metab Care, 2003, 6, 157-163.

[116] Barrera-Arellano, D., Márquez-Ruiz, G., Dobarganes, M.C., A simple procedure to evaluate the performance of fats and oils at frying temperatures. Grasas y Aceites 1997, 48, 231-235.

[117] Gertz, C., Klostermann, S., Parkash-Kochhar, S., Testing and comparing oxidative stability of vegetable oils and fats at frying temperature. Eur. J. Lipid Sci. Technol. 2000, 102, 543-551. 
Table 1.- Characterization of oils (fatty acid composition, total tocoherols and oil stability index) and alteration compounds formed under discontinuous frying conditions and simulated frying in a Rancimat.

\begin{tabular}{llcccc}
\hline & HLSO & HOSO & VOO & VAO \\
\hline Fatty acid composition (\%) & & & & \\
C16:0 & 6.8 & 4.5 & 11.6 & 16.3 \\
C18:0 & 4.9 & 4.3 & 3.1 & 0.6 \\
C18:1 & 21.4 & 72.4 & 76.9 & 62.7 \\
C18:2 & 65.1 & 16.9 & 5.1 & 11.4 \\
C18:3 & 0.1 & 0.1 & 0.7 & 0.8 \\
& & & & \\
Total tocopherols (mg/kg) & 603 & 650 & 204 & 399 \\
& & & & & \\
Oil Stability Index (h) & & 9.0 & 20.8 & 117.0 & 22.1 \\
\hline Discontinuous frying & Polar compounds (\%) & 20.4 & 17.2 & 17.8 & 21.0 \\
$\mathbf{1 8 0}^{\circ} \mathbf{C}, \mathbf{6 h}$ & Polymers (\%) & 12.1 & 8.6 & 8.0 & 9.5 \\
\hline Rancimat & Polar compounds (\%) & 21.9 & 17.8 & 18.7 & 21.9 \\
$\mathbf{1 8 0}^{\circ} \mathbf{C}, \mathbf{1 0 h}$ & Polymers (\%) & 12.3 & 8.3 & 8.4 & 11.1 \\
\hline
\end{tabular}

Abbreviations: HLSO, high-linoleic sunflower oil; HOSO, high-oleic sunflower oil; VOO, virgin olive oil; VAO, virgin avocado oil. 
Figure 1. Formation of polymers (solid lines) and loss of tocopherols (dotted lines) in high-linoleic sunflower oil (filled squares), high-oleic sunflower oil (filled triangles), tocopherol-stripped high-linoleic sunflower oil (void squares) and tocopherol-stripped high-oleic sunflower oil (void triangles) heated at $180^{\circ} \mathrm{C}$.

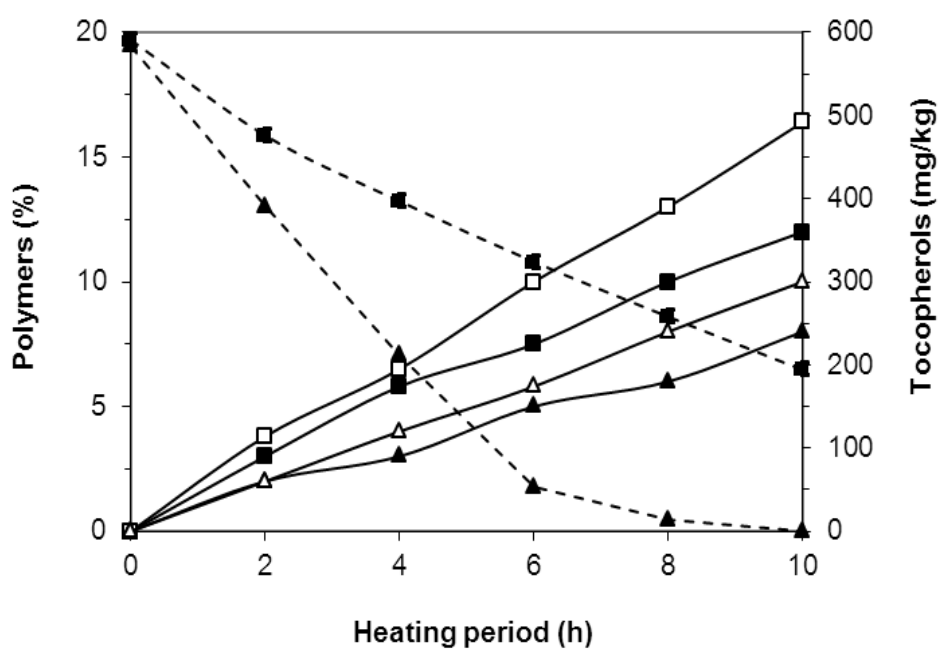


Figure 2. Formation of polar compounds in high-linoleic sunflower oil (HLSO) and high-oleic sunflower oil (HOSO) with or without DMPS during discontinuous (A) and continuous frying (B) at $180^{\circ} \mathrm{C}$.
